On these bases the following table is calculated :-

Excess of the mean stature of the pedigree breed in each successive generation, above that of the rest of the population, when both parents ocatpy the undermentioned grades in their own seneration of the pedigree-breed.

\begin{tabular}{|c|c|c|c|c|c|c|c|c|}
\hline & \multicolumn{3}{|c|}{ Generation. } & $99^{\circ}$ & $95^{\circ}$ & $90^{\circ}$ & $80^{\circ}$ & $70^{\circ}$ \\
\hline I & $\ldots$ & $\ldots$ & $\cdots$ & $\begin{array}{c}\text { inches. } \\
3^{\circ} 9\end{array}$ & $\begin{array}{c}\text { inches. } \\
2.8\end{array}$ & $\begin{array}{c}\text { inches. } \\
2^{\circ} 2\end{array}$ & $\begin{array}{c}\text { inches. } \\
1 \cdot 4\end{array}$ & $\begin{array}{c}\text { inches. } \\
0.9\end{array}$ \\
\hline 2 & $\cdots$ & $\cdots$ & $\ldots$ & $6 \cdot 1$ & $4 \cdot 3$ & 34 & $2 \cdot 2$ & $I \cdot 4$ \\
\hline 3 & $\cdots$ & $\cdots$ & $\cdots$ & 75 & $5^{\circ} 3$ & $4 * I$ & $2 \cdot 7$ & $I^{\circ} 7$ \\
\hline 4 & $\cdots$ & $\cdots$ & $\cdots$ & $8 \cdot 4$ & 6.0 & 47 & $3 \cdot I$ & $I^{\circ} 9$ \\
\hline 5 & $\cdots$ & $\cdots$ & $\ldots$ & $9^{\circ} 1$ & $6: 4$ & $5^{\circ} \mathrm{O}$ & $3 \cdot 3$ & $2 \cdot 1$ \\
\hline \&c. & $\cdots$ & $\cdots$ & $\ldots$ & \&c. & $\& c$. & \&c. & \&c. & \&c. \\
\hline $\operatorname{Lim}$ & ing $v$ & & $\cdots$ & $10 \% 4$ & $7 \bullet 3$ & $5 \cdot 7$ & $3 \cdot 8$ & $2 \cdot 3$ \\
\hline
\end{tabular}

The importance to the breeder, of using highly selected parents, is measutred by these tables, and shown to be very great. Thus one generation of the $99^{\circ}$ selection is seen to be more effective than two generations of the $90^{\circ}$ selection, and to have about equal effects with those of an $80^{\circ}$ selection carried on to perpetuity. Two generations of the $99^{\circ}$ selection are more effective than four of the $95^{\circ}$, and than a per petuity of the $90^{\circ}$.

It must be borne in mind, that there is no stability in a breed improved under the supposed conditions; but that, as soon as selection ceases it will regress to the level of the rest of the population through stages in which the deviation at starting, sinks successively to $w, w w^{2} \ldots w^{n}$ of its value. It may, however, happen that a stable form will arise during the process of high breeding, that shall afford a secondary focus of regression, and become the dominant one, if the ancestral qualities that interfere with it be eliminated by sustained isolation and selection. Then a new variety would, as I conceive, arise ; but into this disputable topic there is no need to enter now.

We can thus understand the facility with which races of butterflies acquire mimetic forms, the severity of selection in their case being very great, while one of their generations occupies only a year.

Francis Galton.

\section{The Effect of Röntgen Rays on Liquid and Solid Insulators.}

Owing to my ausence from Cambridge in the Easter vacation, I have not until to day seen the paper by Lord Kelvin, Dr. Beattie and Dr. M. Smolan (NATURE, March 25), on the influence of Röntgen rays on electric conduction through air, paraffin, and glass, in which the authors state that they cannot detect any influence of Röntgen radiation on conduction through solids. I think that the difference between this result and the one obtained by Mr. McClelland and myself arises from the temporary character of the effect of the radiation on solids. The increase in the conductivity of solids is only appreciable for a short time after the application of the electric force (see NA'UURE, July 30, I 896, p. 306); under long-continued electromotive forces the conductivity seems unaffected by the rays. The effect might perhaps be more accurrately described as an increase in the electric absorption, rather than as an increase in conductivity. I have been for the past few months engaged in experiments on the effect of the rays on solids and liquids, particularly liquids; and, though the experiments have been much interrupted by the pressure of other work, I hope soon to have them ready for publication. There is one experiment, however, which may be of interest. Of all the liquids tried, that sold as vaseline oil has proved the best insulator; in its pure state it is very transparent to Röntgen rays, so to increase the absorption of these rays I stained the oil with iodine, when it became very opaque to them. The oil does not insulate so well after stain. ng as it did before, but the effect of a slight amount of conductivity is not of importance when the following method is used. Three electrodes, A, B, C, are placed in a leaden vessel filled with the oil. $B$, which is between $A$ and $C$, is connected to one pair of quadrants of an electrometer, $\mathrm{A}$ and $\mathrm{C}$ to the terminals of a battery of Iooo small storage cells. If there is any leakage the potential of $B$ will, in general, not remain zero after the hattery is put on, but it will do so if an earth connection is made at the proper place in the battery. The base of the vessel below B C was cut out, and an aluminium vessel inserted, so

$$
\text { NO. I } 435 \text {, VOL. } 55]
$$

that the liquid between $\mathrm{B}$ and $\mathrm{C}$ could be exposed to the Röntgen rays. A balance was obtained with the rays off; when the rays were turned on, the potential of $\mathrm{B}$ no longer remained zero, but changed in the way it would if the conductivity between $B$ and $\mathrm{C}$ had increased. This effect was small but well marked, and seemed to last however long the electromotive force was kept on.

Cavendish Laboratory, April 24.

J. J. THOMSON.

\section{The Theory of Dissociation into Ions.}

Mr. Seencer Pickering has, in your number for January 7 , brought forward certain difficulties which he says the advocates of the dissociation hypothesis have persistently ignored. I have been waiting in the hope that some one who supports the gaseous theory of solution as well as the theory of electrolytic dissociation would answer his letter. As no one has done so, I venture once more to trespass on your space.

First let me say that the experiment described by Mr. Picker. ing, in which water or propyl alcohol exudes through the walls of a semi-permeable vessel containing a mixture of these liquids, according as propyl alcohol or water is placed without, appears to me, as it does to him, to be very strong evidence that it is complex molecules of solution to which the walls are impervious. The experiment is one which certainly needs explanation at the hands of those who uphold the gaseous impact theory of osmotic pressure.

As I have already said, the idea that electrolytic conduct. ivity depends on dissociation of the ions from each other, does not involve, as is so often assumed to be the case, the gaseous view of solution. The evidence for such dissociation appears to me to be exceedingly strong, as I will explain very briefly below, so that some explanation of the second experiment described by Mr. Pickering is necessary.

The experiment is this: The freezing point of a large quantity of acetic acid, to which is added a mixture of sulphuric acid and water in the proportions represented by $\mathrm{LoOH}_{2} \mathrm{O}+\mathrm{H}_{2} \mathrm{SO}_{4}$, shows that considerably less than 100 molecules have been dissolved. This result indicates that chemical union has occurred. Mr. Pickering says that, on the dissociation theory, the freezing point should be lowered by an amount corresponding to something between IOI and IO3 molecules.

In such a case, however, we have conditions very different from those which hold when sulphuric acid is dissolved in water. In fact the liquid is in reality a mixed solution of water and sulphuric acid in acetic acid, or possibly, as Mr. Pickering suggests, of the hydrate of sulphuric acid in acetic acid. It does not at all follow that because sulphuric acid is dissociatec in water, it is, therefore, dissociated in other solvents ; in fact, the freezing points of its solutions in acetic acid show that, on the contrary, aggregation has occurred. We should, therefore, expect that dissolving sulphuric acid in acetic acid would have little or no effect on the conductivity; and this is also indicated by the low specific inductive capacity of acetic acid, which implies a low ionising power. There is no reason to suppose that the presence of a small quantity of water would modify the properties of the solvent enough to cause any appreciable change in the conditions.

But, even if these considerations were insufficient to explain the facts, the dissociation theory would not be discredited. As I pointed out in your issues of October I 5 and Decemher I7, I896, dissociation of the ions from each other does not forbid the assumption that the ions are linked with one or more solvent molecules. Such a combination would explain Mr. Pickering's observation.

Mr. Pickering says that the dissociation theory depends solely on the numerical agreement obtained wher properties of solutions are interpreted by its means. Although these numerical relations may have suggested the theory, they by no means furnish the only basis for it to rest upon. Other facts, to my mind, give much more conclusive evidence in its favour. As Mr. Pickering has challenged the supporters of the theory to explain his experiment, I may be allowed to ask the opponents of the theory to explain the following phenomena in any other way than by a dissociation of the ions from each other :-

(I) The velocity with which an ion travels through a dilute solution under an electric force is independent of the nature of the other ion present.

(2) 'The conductivity of a dilute solution is proportional to its concentration. The alternative to the idea of dissociation is to 